\title{
Thermodynamic analysis of two-step solar water splitting with mixed iron oxides
}

\author{
Martin Roeb, Nils Gathmann, Martina Neises ${ }^{* \dagger}$, Christian Sattler and Robert Pitz-Paal \\ German Aerospace Center (DLR), Institute of Technical Thermodynamics, Solar Research, 51147 Köln, Germany
}

\begin{abstract}
SUMMARY
A two-step thermochemical cycle for solar production of hydrogen from water has been developed and investigated. It is based on metal oxide redox pair systems, which can split water molecules by abstracting oxygen atoms and reversibly incorporating them into their lattice. After successful experimental demonstration of several cycles of alternating hydrogen and oxygen production, the present work describes a thermodynamic study aiming at the improvement of process conditions and at the evaluation of the theoretical potential of the process.

In order to evaluate the maximum hydrogen production potential of a coating material, theoretical considerations based on thermodynamic laws and properties are useful and faster than actual tests. Through thermodynamic calculations it is possible to predict the theoretical maximum output of $\mathrm{H}_{2}$ from a specific redox-material under certain conditions. Calculations were focussed on the two mixed iron oxides nickel-iron-oxide and zinc-iron-oxide. In the simulation the amount of oxygen in the redox-material is calculated before and after the water-splitting step on the basis of laws of thermodynamics and available material properties for the chosen mixed iron oxides. For the simulation the commercial Software FactSage and available databases for the required material properties were used.

The analysis showed that a maximum hydrogen yield is achieved if the reduction temperature is raised to the limits of the operation range, if the temperature for the water splitting is lowered below $800^{\circ} \mathrm{C}$ and if the partial pressure of oxygen during reduction is decreased to the lower limits of the operational range. The predicted effects of reduction temperature and partial pressure of oxygen could be confirmed in experimental studies. The increased hydrogen yield at lower splitting temperatures of about $800^{\circ} \mathrm{C}$ could not be confirmed in experimental results, where a higher splitting temperature led to a higher hydrogen yield. As a consequence it can be stated that kinetics must play an important role especially in the splitting step. Copyright (C) 2009 John Wiley \& Sons, Ltd.
\end{abstract}

KEY WORDS: mixed iron oxides; ferrite; thermochemical cycle; water splitting; hydrogen; thermodynamics

\section{INTRODUCTION}

Hydrogen is one of the most promising options for storing and transportation of solar energy [1]. It can be produced from water by electrolysis with electricity coming from solar power, but this technology is currently expensive and has a low total efficiency. Thermochemical cycles appear to be a promising alternative, which potentially offer both, higher efficiencies and lower costs [2].

\footnotetext{
*Correspondence to: Martina Neises, German Aerospace Center (DLR), Institute of Technical Thermodynamics, Solar Research, 51147 Köln, Germany.

${ }^{\dagger}$ E-mail: martina.neises@dlr.de

Contract/grant sponsor: European Commission; contract/grant number: SES6-CT-2005-020030
} 
A promising family of thermochemical cycles is the two-step water-splitting cycle using redox systems. During the first step of this cycle (watersplitting step) the reduced and therefore activated material is oxidized by abstracting oxygen from water and producing hydrogen. In the next step (the reduction step) the material is reduced again, setting some of its lattice oxygen free.

Several redox materials consisting of oxide pairs of multivalent metals (e.g. $\mathrm{Fe}_{3} \mathrm{O}_{4} / \mathrm{FeO}$ [3,4], $\mathrm{Mn}_{3} \mathrm{O}_{4} / \mathrm{MnO}$ [5]) or systems of metal oxide/metal (e.g. $\mathrm{ZnO} / \mathrm{Zn} \mathrm{[6])} \mathrm{have} \mathrm{been} \mathrm{evaluated} \mathrm{for} \mathrm{such}$ applications. Recently a lot of attention has been laid on ferrites and mixed iron oxides [7-9] and different approaches on solar receiver concepts for using mixed ferrites [10-12] have been developed.

In the scope of the project HYDROSOL and the consecutive project HYDROSOL-2, both funded by the EC, mixed iron oxides have been used as redox materials [13]. The basic idea was to combine a support structure capable of achieving high temperatures when heated by concentrated solar radiation, with a redox pair system suitable for the performance of water dissociation and for reduction at these temperatures. In particular, the iron oxides have been fixed on ceramic honeycomb monolithic structures, which are placed inside a solar receiver reactor. With this approach, complete operation of the whole process (water splitting and reduction of the metal oxide) can be achieved with a single solar energy converter. The process has been tested in the solar furnace of DLR in Cologne resulting in the proof of principle, in proving the 'cyclability' of the involved materials, and in performing parametric studies. The redox systems favoured in HYDROSOL-2 are zinc and nickel/zinc based ferrites. The reaction scheme in the case of zinc can be written as follows:

water-splitting

$$
\begin{aligned}
& \mathrm{ZnFe}_{y}^{2+} \mathrm{Fe}_{2-y}^{3+} \mathrm{O}_{4-y / 2}+x \mathrm{H}_{2} \mathrm{O} \\
& \quad \rightarrow \mathrm{ZnFe}_{y-x / 2}^{2+} \mathrm{Fe}_{2-y+x / 2}^{3+} \mathrm{O}_{4-y / 2+x}+x \mathrm{H}_{2}
\end{aligned}
$$

reduction

$$
\begin{aligned}
& \mathrm{ZnFe}_{y-x / 2}^{2+} \mathrm{Fe}_{2-y+x / 2}^{3+} \mathrm{O}_{4-y / 2+x} \\
& \quad \rightarrow \mathrm{ZnFe}_{y}^{2+} \mathrm{Fe}_{2-y}^{3+} \mathrm{O}_{4-y / 2}+\frac{x}{2} \mathrm{O}_{2}
\end{aligned}
$$

In practise solid solutions are formed containing various metal oxide species. Therefore, (1) and (2) have to be looked upon as simplified schemes.

The results from the solar furnace experimental campaigns are essential for the comparative evaluation of the developed coating materials. For the coating material the oxygen uptake capability of a material is an essential characteristic, because it is directly connected to the amount of hydrogen, which can be produced with a certain redox-material. In order to evaluate the maximum oxygen uptake potential of a coating material as well as to predict suitable operational conditions and to be able to find new materials, theoretical considerations based on thermodynamic laws and properties are helpful and faster than actual tests. Through thermodynamic calculations it is possible to predict the theoretical maximum output of $\mathrm{H}_{2}$ a redox-material can produce under certain conditions. Within the present theoretical work, a simulation based on thermodynamic considerations was performed for the two mixed iron oxides nickel-iron-oxide (Ni-Fe-oxide) and zinc-iron-oxide ( $\mathrm{Zn}-\mathrm{Fe}-$ oxide).

\section{METHODOLOGY}

In the simulation the amount of oxygen in the redox-material is calculated before and after the splitting step on the basis of laws of thermodynamic and available material properties for the above-mentioned mixed iron oxides. For the simulation the commercial Software FactSage [14] and available databases of the necessary material properties were used. The software is able to include non-stoichiometric phases in its calculations and has turned out suitable to handle the relevant metal oxide systems [15]. With this software it was possible to calculate the amount of oxygen in the iron oxide, which is reached in the state of equilibrium under certain conditions. When the amount of oxygen in the material is known, the hydrogen produced during a watersplitting step can be calculated.

Within the work the influence of the most important operational parameters like temperature on the hydrogen output were investigated. 
The results of the thermodynamic calculations can then be compared with the results observed in the solar furnace. Furthermore the results can help optimizing the operating parameters of the process as well as finding new materials, which are worth investigating in the future.

For the calculations it is assumed that the metal oxide reaches a thermodynamic equilibrium. It is furthermore assumed that the oxygen content in the metal oxide does not change during heating and cooling phases and that during the reduction step a flushing gas is used. Argon was chosen as the flushing gas and the partial pressure of oxygen in argon was set to be $10^{-6}$ bar. Nitrogen, which is used in the actual tests in the solar furnace, was disregarded because of possible reactions between nitrogen and oxygen at temperatures above $1200^{\circ} \mathrm{C}$. For the water-splitting step it is assumed that the metal oxide is oxidized with pure water vapour without a diluting gas.

Furthermore radiation losses, convective losses and friction losses were disregarded in the calculations.

The influences of the following parameters on the hydrogen output were investigated with the procedure described above.

The investigated parameters were:

- Temperature during the water-splitting step $T_{\text {Split }}=600,700,900,1000,1100,1200^{\circ} \mathrm{C}$

- Temperature during the reduction step $T_{\text {Red }}=1000,1100,1300,1400^{\circ} \mathrm{C}$

- Partial pressure of oxygen in the flushing gas during the reduction step $p_{\mathrm{O}_{2, \text { red }}}=10^{-9}, 10^{-8}$, $10^{-7}, 10^{-5}$ bar

- Composition of the metal oxide $Y_{\mathrm{Zn}}$ and $Y_{\mathrm{Ni}}$ resp. $=20,33,50,60 \%$

All calculations are based on thermodynamic data of the relevant chemical compounds and of the phases they form. In particular this requires the determination of absolute enthalpies, Gibbs enthalpies and entropies of the pure compounds depending on temperature as well as the enthalpies and entropies of the mixed iron oxide depending on temperature and composition. Beyond that the equilibrium composition of the solid and the surrounding gas phase need to be determined for different temperatures and metal oxide compositions. Those data were calculated with the mentioned software FactSage applying the databases FACT53 for pure substances, FToxid53 for stoichiometric metal oxides and FToxid53SOLN for metallic solutions. The determination of equilibrium states accounted for changes of Gibbs enthalpy due to incorporation of atoms into interstitial sites of the lattice, due to substitutions and magnetism. Real gas models were applied for the components of the gas phase.

The processing of these thermodynamic data, the determination of derived terms and interdependencies was conducted by an Excel spreadsheet.

\section{THERMODYNAMIC APPROACH}

In the thermodynamic calculations the thermodynamic equilibrium composition of the system consisting of the solid metal oxide and a gas phase was calculated. In the splitting step and in the reduction step, oxygen atoms are exchanged between the gas phase and the metal oxide. In the thermodynamic equilibrium the rate at which atoms are exchanged in both directions is the same and the equilibrium composition is reached. Is a parameter changed within the system, it will adapt until a new thermodynamic state of equilibrium is reached.

During the water-splitting step and the reduction of a two-step thermochemical cycle the metal oxide is oxidized and reduced again resulting in a permanent change of the oxygen content in the metal oxide. The oxygen content in the metal oxide $Y_{\mathrm{O}_{2}}$ can be defined as the amount of oxygen molecule-equivalents divided by the amount of metal molecules in a metal-oxide:

$$
Y_{\mathrm{O}_{2}}=\frac{n_{\mathrm{O}_{2}}}{n_{\mathrm{Me}}}
$$

In the thermodynamic equilibrium a certain partial pressure of oxygen in the gas phase is reached. It depends on the composition of the metal oxide and the temperature in the system and is named in the following $p_{\mathrm{O}_{2}}^{\mathrm{Me}}$. Now we assume the gas over the metal-oxide is continually exchanged through another gas with a defined oxygen content. The 
partial pressure of oxygen in this input gas is essential for the evaluation of the oxygen content in the metal oxide. The oxygen content in the metal-oxide will change until the partial pressure of oxygen in equilibrium $p_{\mathrm{O}_{2}}^{\mathrm{Me}}$ is equal to the partial pressure of oxygen in the input gas.

Before the water-splitting step the system is in thermodynamic equilibrium and the metal oxide has a defined oxygen content $Y_{\mathrm{O}_{2}}$. Now water vapour is constantly put into the system. The water dissociates partially into hydrogen and oxygen because of the elevated temperature. We assume that the input gas is in its thermodynamic equilibrium and consists of water, hydrogen and oxygen. The partial pressure of oxygen in the gas phase is equal to the equilibrium partial pressure of oxygen for the thermal dissociation of water at that certain temperature.

The metal oxide is now going to take up oxygen atoms out of the gas phase as long as $Y_{\mathrm{O}_{2}}$ reaches the value where $p_{\mathrm{O}_{2}}^{\mathrm{Me}}$ is equal to the partial pressure of oxygen in the input gas.

Figure 1 shows the determination of $Y_{\mathrm{O}_{2}}$ after a water-splitting step at $1000^{\circ} \mathrm{C}$ for a certain $\mathrm{Ni}-\mathrm{Fe}$-oxide when the thermodynamic equilibrium is reached. The graph shows the correlation between $p_{\mathrm{O}_{2}}^{\mathrm{Me}}$ and $Y_{\mathrm{O}_{2}}$. A very small change in oxygen partial pressure is reflected in a rather wide range of compositional change (between $Y_{\mathrm{O}_{2}}=0.52-0.62$ ) because in that state different components are in equilibrium with the given oxygen partial pressure, which remains the same until one component has transformed completely into the other. As well the partial pressure of oxygen for the thermal dissociation of water at $1000^{\circ} \mathrm{C}$ is drawn into the plot as a horizontal line. It is about $10^{-5}$ bar. When $p_{\mathrm{O}_{2}}^{\mathrm{Me}}$ is equal to the partial pressure of oxygen for the dissociation of water, the thermodynamic equilibrium between the gas phase and the metal oxide is reached and a stable value of $Y_{\mathrm{O}_{2}}$ has adjusted and can be read off (vertical line in Figure 1). That means the oxygen content in the metal oxide $Y_{\mathrm{O}_{2}}$ that is reached in the thermodynamic equilibrium in the splitting step can be determined when the partial pressure of oxygen in the dissociated water vapour and the correlation between $Y_{\mathrm{O}_{2}}$ and $p_{\mathrm{O}_{2}}^{\mathrm{Me}}$ is known.

For the reduction step the approach is similar. Now we assume argon with a partial pressure of oxygen of $10^{-6}$ bar is continuously added to the system. That means that $p_{\mathrm{O}_{2}}^{\mathrm{Me}}$ in the thermodynamic equilibrium is equal to $10^{-6}$ bar. Figure 2 shows how $Y_{\mathrm{O}_{2}}$ can be determined after a reduction step at $1200^{\circ} \mathrm{C}$ for a certain $\mathrm{Ni}-\mathrm{Fe}-$ oxide. The correlation

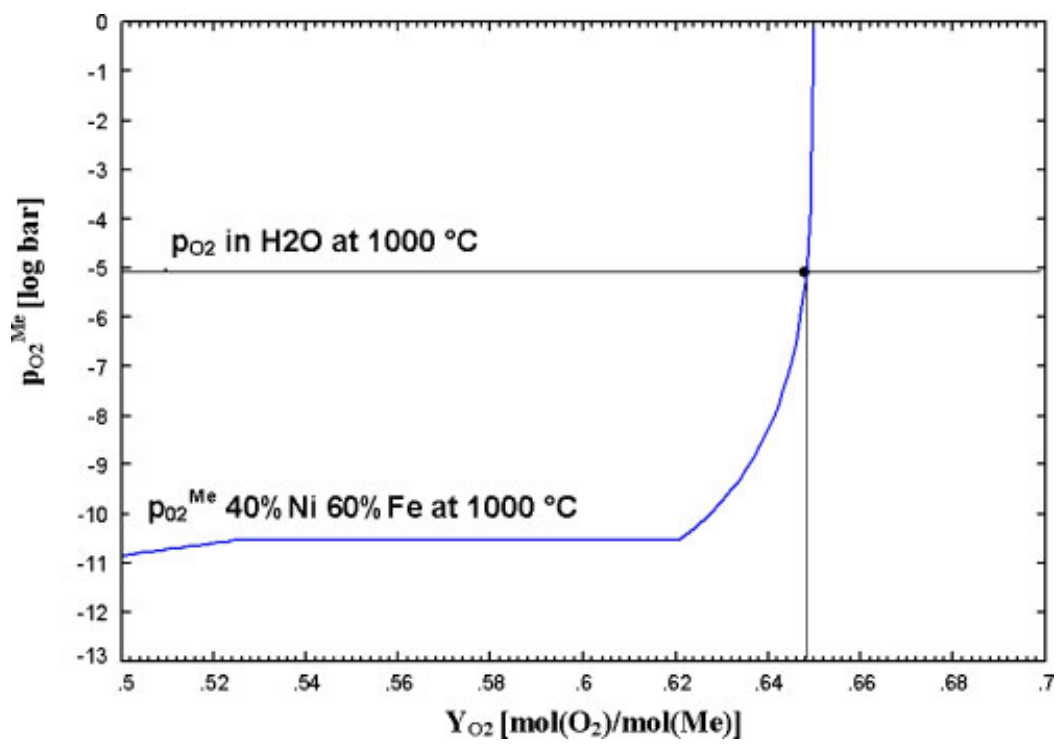

Figure 1. Determination of $Y_{\mathrm{O}_{2}}$ after a water-splitting step at $1000^{\circ} \mathrm{C}$ for a nickel-iron-oxide $\mathrm{Ni}(40 \%)-\mathrm{Fe}(60 \%)$-oxide. 


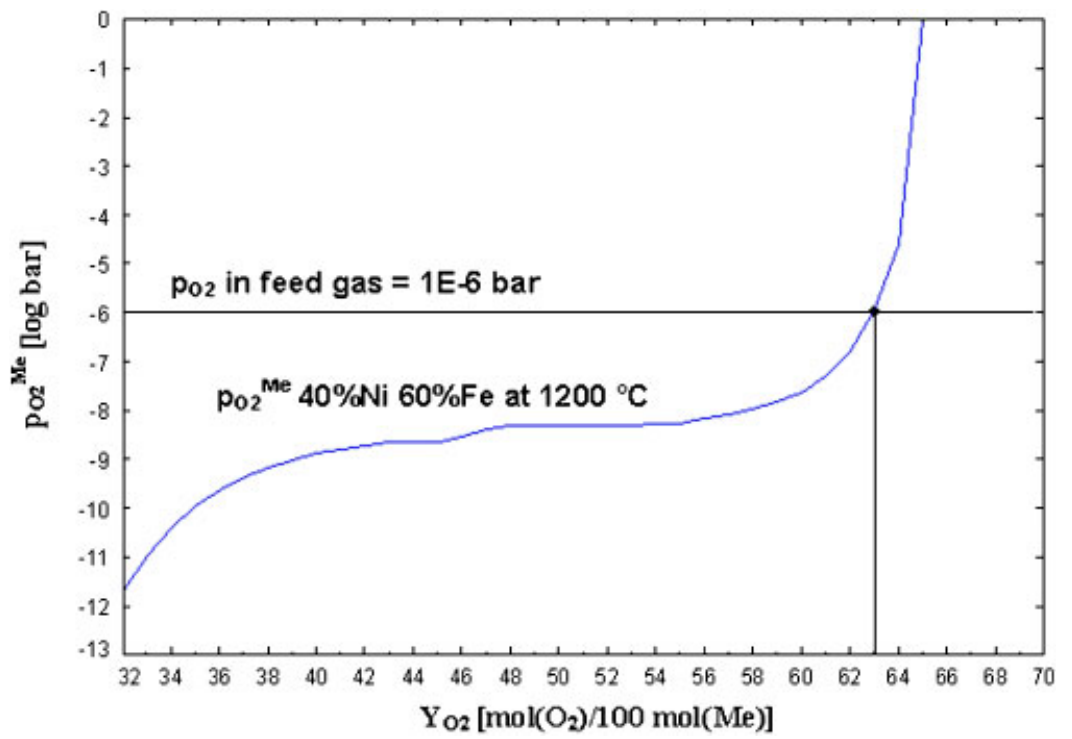

Figure 2. Determination of $Y_{\mathrm{O}_{2}}$ after the reduction step at a temperature of $1200^{\circ} \mathrm{C}$ for a nickel-iron-oxide $\mathrm{Ni}(40 \%)-\mathrm{Fe}(60 \%)$-oxide.

for $Y_{\mathrm{O}_{2}}$ and $p_{\mathrm{O}_{2}}^{\mathrm{Me}}$ at $1200^{\circ} \mathrm{C}$ is shown in Figure 2. The horizontal line depicts the partial pressure of oxygen in the input gas, in this case $10^{-6}$ bar. At the intercept point the oxygen content $Y_{\mathrm{O}_{2}}$ after the reduction step can be read off (vertical line).

With this approach the oxygen content $Y_{\mathrm{O}_{2}}$ after the water-splitting step and after the reduction step in thermodynamic equilibrium can be determined. The hydrogen which is produced during a water-splitting step can be calculated as follows when the oxygen content $Y_{\mathrm{O}_{2}}$ before $Y_{\mathrm{O}_{2,1}}$ and after the splitting step $Y_{\mathrm{O}_{2,2}}$ is known.

$$
Y_{\mathrm{O}_{2,2}}-Y_{\mathrm{O}_{2,1}}=\frac{n_{\mathrm{O}_{2,2}}-n_{\mathrm{O}_{2,1}}}{n_{\mathrm{Me}}}=\frac{n_{\mathrm{O}_{2,1-2}}}{n_{\mathrm{Me}}}=\frac{n_{\mathrm{H}_{2,1-2}}}{2^{*} n_{\mathrm{Me}}}
$$

\section{RESULTS AND ANALYSIS}

\subsection{Influence of water-splitting temperature}

Figure 3 shows the hydrogen yield dependent on the water-splitting temperature $T_{\text {Split }}$ for a $\mathrm{Zn}-\mathrm{Fe}$ oxide and for a $\mathrm{Ni}-\mathrm{Fe}$-oxide system. As can be seen the hydrogen yield decreases with increasing temperature. A closer look at the slope of the curves points out that in the temperature range below about $1000^{\circ} \mathrm{C}$ the influence of water-splitting temperature on yield is rather low. Therefore it is possible to conduct the watersplitting step at rather high temperatures up to $1000^{\circ} \mathrm{C}$ without significant losses of yield. This ensures positive effects on reaction kinetics and an enhancement of thermal efficiency, since thermal losses due to temperature cycling decrease.

Although the thermodynamic simulations predict that a lower water-splitting temperature of about $800^{\circ} \mathrm{C}$ is more favourable for the hydrogen output, the results in the solar furnace lead to opposite conclusions [12]. The discrepancy between the experimental results obtained in the solar furnace test and the thermodynamic calculations lead to the conclusion that kinetics play an important role especially in the watersplitting step. Because of this disagreement kinetic investigations are highly recommended.

\subsection{Influence of reduction temperature}

In Figure 4 the series of curves depicted exemplarily for the nickel-based redox system for different reduction temperatures indicates that $Y_{\mathrm{O}_{2}}$ decreases if the reduction temperature increases for a constant $p_{\mathrm{O}_{2}}^{\mathrm{Me}}$. After completion of the reduction 


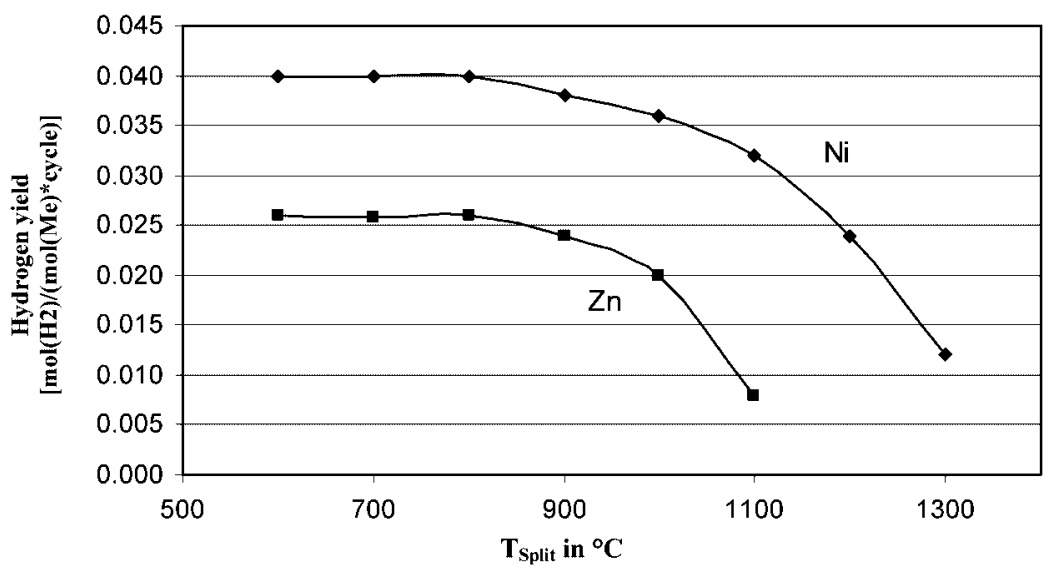

Figure 3. Hydrogen yield versus water-splitting temperature $\left(T_{\mathrm{Red}}=1200^{\circ} \mathrm{C} ; p_{\mathrm{O}_{2}}^{\mathrm{Red}}=10^{-6} \mathrm{bar} ; \quad Y_{\mathrm{Me}, \mathrm{nf}}=40 \%\right.$, $\left.\mathrm{Me}_{\mathrm{nf}}=\mathrm{Zn} / \mathrm{Ni}\right)$.

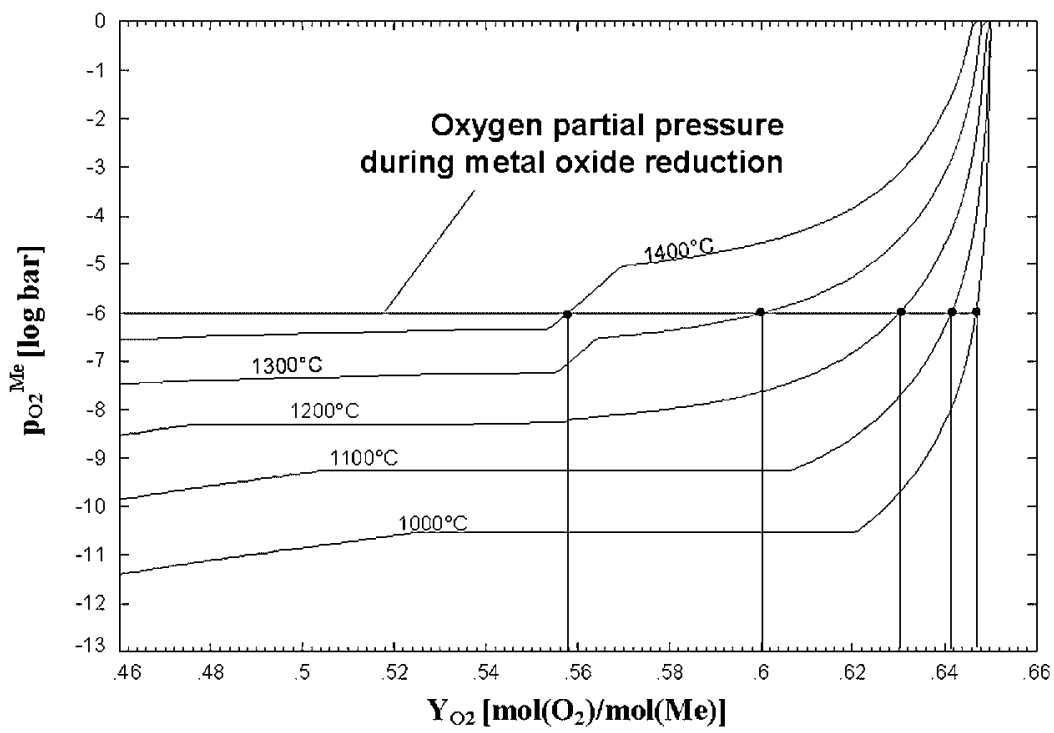

Figure 4. Dependency of $p_{\mathrm{O}_{2}}^{\mathrm{Me}}$ on $Y_{\mathrm{O}_{2}}$ for a nickel-iron-oxide $\left(Y_{\mathrm{Ni}}=40 \%\right)$ at different reduction temperatures $\left(p_{\mathrm{O}_{2}}^{\mathrm{Red}}=10^{-6}\right.$ bar $)$.

step $p_{\mathrm{O}_{2}}^{\mathrm{Me}}$ is equal to the partial pressure of the adjacent gas phase. Therefore, with higher reduction temperatures a lower $Y_{\mathrm{O}_{2}}$ can be reached. The influence of the reduction temperature $T_{\text {Red }}$ on the hydrogen yield is shown in Figure 5 for a $\mathrm{Zn}-\mathrm{Fe}$ oxide system and for a Ni-Fe-oxide system. From the plot it is clear that the hydrogen yield increases with increasing reduction temperature.
4.3. Influence of partial pressure of oxygen in the reduction step

$Y_{\mathrm{O}_{2}}$ decreases overproportionally during the metal oxide reduction if the oxygen partial pressure is decreased within a range between $10^{-8}$ and $10^{-9}$ bar (Figure 6). This is due to the flat slope of the curve describing the dependency 


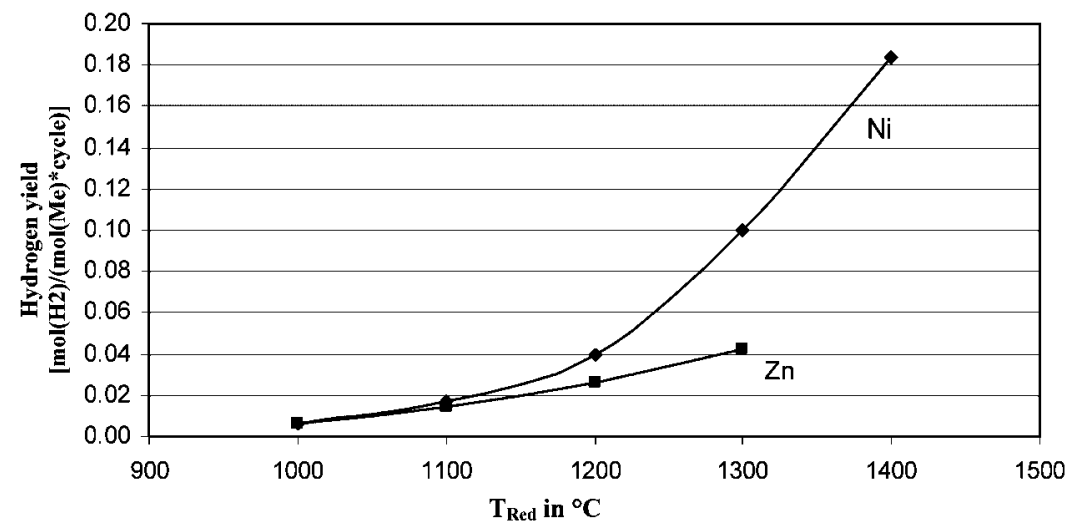

Figure 5. Hydrogen yield versus reduction temperature $\left(T_{\mathrm{Split}}=800^{\circ} \mathrm{C} ; p_{\mathrm{O}_{2}}^{\mathrm{Red}}=10^{-6} \mathrm{bar} ; Y_{\mathrm{Me}, \mathrm{nf}}=40 \%, \mathrm{Me}_{\mathrm{nf}}=\mathrm{Zn} / \mathrm{Ni}\right)$.

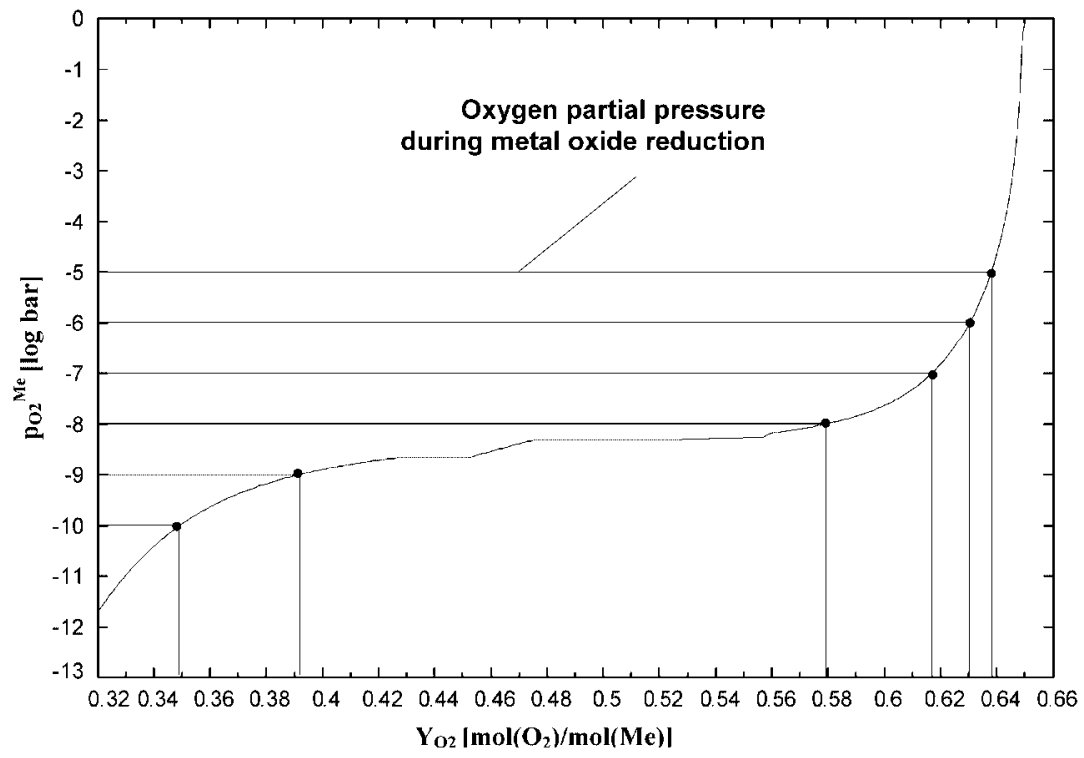

Figure 6. Dependency of $p_{\mathrm{O}_{2}}^{\mathrm{Me}}$ on $Y_{\mathrm{O}_{2}}\left(T_{\mathrm{Red}}=1200^{\circ} \mathrm{C} ; Y_{\mathrm{Ni}}=40 \%\right)$. Vertical lines indicate $Y_{\mathrm{O}_{2}}$ after completion of metal oxide reduction at the corresponding oxygen partial pressure.

of $p_{\mathrm{O}_{2}}^{\mathrm{Me}}$ on $Y_{\mathrm{O}_{2}}$ in that specific range. The slope of that curve is much steeper for higher partial pressures.

Since the difference of $Y_{\mathrm{O}_{2}}$ before and after the metal oxide reduction determines the oxygen uptake capacity, also the hydrogen yield increases if the oxygen partial pressure is lowered for the reduction step (Figure 7). The influence of the partial pressure of oxygen in the flushing gas during the reduction step is shown in Figure 7 for a $\mathrm{Zn}$-Fe-oxide system and for a $\mathrm{Ni}$-Fe-oxide system. It can be seen that as the partial pressure decreases up to $10^{-9}$ bar the hydrogen yield increases drastically.

The impact of the oxygen partial pressure is stronger than that of the other parameters. A lowering of this partial pressure within the discussed range may result in an increase of hydrogen yield of more than one order of magnitude. 


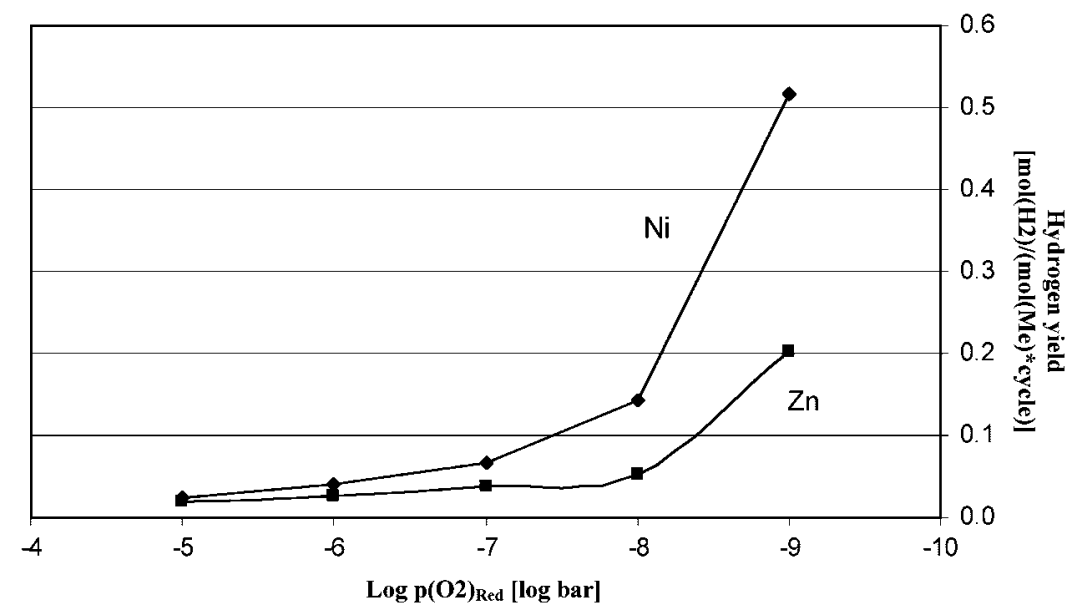

Figure 7. Hydrogen yield versus partial pressure of oxygen during the reduction step $p_{\mathrm{O}_{2}}^{\text {Red }}\left(T_{\mathrm{Split}}=800^{\circ} \mathrm{C}\right.$; $\left.T_{\mathrm{Red}}=1200^{\circ} \mathrm{C} ; Y_{\mathrm{Me}, \mathrm{nf}}=40 \%, \mathrm{Me}_{\mathrm{nf}}=\mathrm{Zn} / \mathrm{Ni}\right)$.

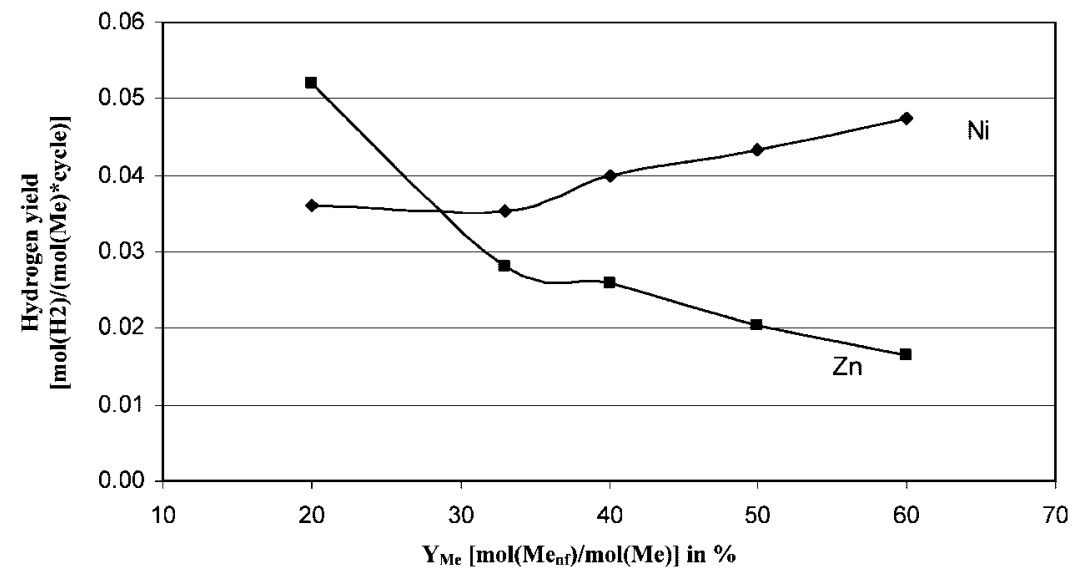

Figure 8. Hydrogen yield versus the non-ferous metal content in the metal oxide $Y_{\mathrm{Me}, \mathrm{nf}}\left(T_{\mathrm{Split}}=800^{\circ} \mathrm{C} ; T_{\mathrm{Red}}=1200^{\circ} \mathrm{C}\right.$; $p_{\mathrm{O}_{2}}^{\text {red }}=10^{-6}$ bar).

\subsection{Influence of the composition of the metal oxide}

Figure 8 shows the influence of the amount of non-ferrous metal-nickel or zinc - in the mixed iron oxide system on the hydrogen yield. The hydrogen yield decreases with increasing zinc content $Y_{\mathrm{Zn}}$. The behaviour of the nickel system is different. There is a minimum hydrogen output at a ratio of about $35 \% \mathrm{Ni}$ to total metal content. For higher amounts of nickel the hydrogen output increases.

\section{CONCLUSIONS}

The thermodynamic simulations predict that for a high hydrogen yield the reduction temperature should be as high as possible. In the actual experiments the reduction temperature is restricted through materials' stability to below $1300^{\circ} \mathrm{C}$. The partial pressure of oxygen in the flushing gas during the metal oxide reduction should be as low as possible. The partial pressure is though limited by the technical possibilities concerning gas 
purities as well as by the price, since a higher gas quality also leads to higher prices for the flushing gas. The thermodynamic simulations indicate a negative effect of increasing the water-splitting temperature on hydrogen yield. This is contradictory to the experiments, which is most probably due to domination of reaction kinetics. An extensive comparison with experimental data will be given in a future contribution.

Regarding the composition of the material it was shown in the thermodynamic simulations that for the zinc-iron-oxide lower zinc contents are favourable for the hydrogen yield. For the nickel-iron-oxide the nickel content showed only a minor influence on the hydrogen yield. Based on the thermodynamic results, investigations of the nickel iron-oxide system seem to be worth, because the hydrogen output is predicted to be not strongly dependent on the composition of the metal-oxide and for most operational conditions better than for the zinc-iron-oxide. A synthesis of nickel iron-oxide and subsequent tests in the laboratory and in the solar furnace are recommended.

\section{NOMENCLATURE}

$\begin{array}{ll}\mathrm{Me} & =\text { metal } \\ \mathrm{Me}_{\mathrm{nf}} & =\text { non-ferrous metal } \\ \mathrm{Ni}-\mathrm{Fe}-\text { oxide } & =\text { nickel-iron-oxide } \\ p_{\mathrm{O}_{2}} & =\text { partial pressure of oxygen } \\ p_{\mathrm{O}_{2}}^{\mathrm{Me}} & =\text { partial pressure of oxygen in gas } \\ & \text { phase in equilibrium with the } \\ & \text { metal oxide } \\ \mathrm{Red} & \text { reduction } \\ \mathrm{Split} & =\text { water splitting } \\ T_{\mathrm{red}} & \text { process temperature of the } \\ & \text { metal oxide reduction step } \\ T_{\mathrm{split}} & \text { process temperature of the } \\ & \text { water-splitting step (metal oxide } \\ & \text { oxidation) } \\ Y_{\mathrm{O}_{2}} & \text { molar ratio of oxygen molecule } \\ & \text { equivalents to metal in the metal } \\ & \text { oxide } \\ Y_{\mathrm{Zn}} & \text { molar ratio of Zn to total metal } \\ & \text { in the metal oxide }\end{array}$

\author{
$Y_{\mathrm{Ni}} \quad=$ molar ratio of Ni to total metal \\ in the metal oxide \\ $\mathrm{Zn}$-Fe-oxide = zinc-iron-oxide
}

\section{ACKNOWLEDGEMENTS}

The authors would like to thank the European Commission for co-funding the project HYDROSOL-2 in the sixth framework program (contract number SES6CT-2005-020030).

\section{REFERENCES}

1. Turner J, Sverdrup G, Mann MK, Maness P-C, Kroposki B, Ghirardi M, Evans RJ, Blake D. Renewable hydrogen production. International Journal of Energy Research 2008; 32:379-407.

2. Eisenstadt MM, Cox KE. Hydrogen production from solar energy. Solar Energy 1975; 17:59-65.

3. Steinfeld A, Sanders S, Palumbo R. Design aspects of solar thermochemical engineering - a case study: two-step watersplitting cycle using the $\mathrm{Fe}_{3} \mathrm{O}_{4} / \mathrm{FeO}$ redox system. Solar Energy 1999; 65(1):43-53.

4. Tsuji M, Togawa T, Wada Y, Sano T, Tamaura Y. Kinetic study of the formation of cation-excess magnetite. Journal of the Chemical Society-Faraday Transactions 1995; 91(10): 1533-1538.

5. Sturzenegger $M$, Nüesch $P$. Efficiency analysis for manganese-oxide-based thermochemical cycle. Energy 1999; 24 959-970.

6. Steinfeld A. Solar hydrogen production via a two-step water splitting thermochemical cycle based on $\mathrm{Zn} / \mathrm{ZnO}$ redox reactions. International Journal of Hydrogen Energy 2002; 27:611-619.

7. Kodama T, Gokon N. Thermochemical cycles for high temperature solar hydrogen production. Chemical Reviews 2007; 107:4048-4070.

8. Han SB, Kang TB, Joo OS, Jung KD. Water splitting for hydrogen production with ferrites. Solar Energy 2007; 81:623-628.

9. Agrafiotis C, Roeb M, Konstandopoulos AG, Nalbandian L, Zaspalis VT, Sattler C, Stobbe P, Steele AM. Solar water splitting for hydrogen production with catalytic monolithic reactors. Solar Energy 2005; 79:409-421.

10. Kaneko H, Fuse A, Miura T, Ishihara H, Tamaura Y. Two-step water splitting with concentrated solar heat using rotary-type solar furnace. 13th Solar PACES International Symposium, SolarPaces, Seville, Spain, June 20-23; 2006.

11. Diver Jr RB, Miller JE, Allendorf MD, Siegel NP, Hogan RE. Solar thermochemical water-splitting ferritecycle heat engines. Proceedings of ISEC 2006 ASME International Solar Energy Conference, Denver, Colorado, July $8-13 ; 2006$.

12. Roeb M, Monnerie N, Schmitz M, Sattler C, Konstandopoulos AG, Agrafiotis C, Zaspalis VT, Nalbandian L, Steele A, Stobbe P. Thermo-chemical production of hydrogen from water by metal oxides fixed 
on ceramic substrates. Proceedings of the 16th World Hydrogen Energy Conference, Lyon, France, June 13-16; 2006.

13. Roeb M, Sattler C, Klüser R, Monnerie N, deOliveira L, Konstandopoulos AG, Agrafiotis C, Zaspalis VT, Nalbandian L, Stobbe P, Steele AM. Solar hydrogen production by a two-step cycle based on mixed iron oxides. Journal of Solar Energy Engineering 2006; 128: $125-133$.
14. Bale CW, Chartrand P, Degterov SA, Eriksson G, Hack K, Mahfoud RB, Melancon J, Pelton AD, Petersen S. FactSage Thermochemical Software and Databases, 2002, Calphad, 26, 189; 2002.

15. Allendorf MD, Diver Jr RB, Miller JE, Siegel NP. Thermodynamic analysis of mixed-metal ferrites for hydrogen production by two-step water splitting. Proceedings of ISEC 2006 ASME International Solar Energy Conference, Denver, Colorado, July 8-13; 2006. 